\title{
Effects of phenological stages on yield and composition of essential oil of Syzygium aromaticum buds from Madagascar
}

\author{
Gaylor Razafimamonjison $^{1,2,3_{*}}$, Michel Jahiel ${ }^{2,3,4}$, Panja Ramanoelina ${ }^{1}$, Fanja Fawbush ${ }^{1}$, Pascal Danthu ${ }^{2,5}$ \\ ${ }^{1}$ Université d'Antananarivo, École Supérieure des Sciences Agronomiques, BP 175, Antananarivo, Madagascar \\ ${ }^{2}$ DP Forêts et Biodiversité, BP 853, Antananarivo, Madagascar \\ ${ }^{3}$ Centre Technique Horticole de Tamatave, BP 11, Tamatave, Madagascar \\ ${ }^{4}$ CIRAD, UPR Hortsys, PS4, Boulevard de la Lironde, 34392 Montpellier Cedex 05, France \\ ${ }^{5}$ CIRAD, UR 105, Campus de Baillarguet, 34392 Montpellier Cedex 05, France \\ *Corresponding author E-mail: rdinagaylor@yahoo.fr
}

\begin{abstract}
Variation on yield and composition of the essential oil of Syzygium aromaticum buds from Madagascar at different phenological stages including young bud stage, budding stage 1, budding stage 2 , budding stage 3 , full budding stage, flowering stage, initial fruiting stage, full fruiting stage are reported. The essential oil yield varied from $2.52 \%$ to $17.94 \%$, reaching a maximum at the end of budding stage, after which it rapidly decreased. The essential oil was analyzed by GC and four constituents were identified and quantified for whole phenological stages. Eugenol and eugenyl acetate were the main compounds in all samples. Eugenol, was lower in the young bud stage (39.66\%) and increased in the subsequent phenological stages to reach maximum in the full fruiting stage (94.89\%). In contrast, eugenyl acetate was higher in the young bud stage $(56.07 \%)$, after which decreased to reach minimum in the full fruiting stage $(2.01 \%)$.
\end{abstract}

Keywords: chemical composition; essential oil; phenological stages; Syzygium aromaticum buds; yield.

\section{Introduction}

The clove tree (Syzygium aromaticum Merrill \& Perry), Myrtaceae is a perennial tropical plant which grows to a height ranging from 10 to $20 \mathrm{~m}$, having large oval leaves and crimson flowers in numerous groups of terminal clusters. The clove tree is native to Moluccas Island (Indonesia) [1]. Two major clove products are available and marketed: the clove which is the unopened green fully - grown buds upon drying, and the essential oil extracted either from bud, leaf, stem or fruit [2-4].

In the early eighteenth century, the clove tree was introduced in different parts of the world: Zanzibar, India and Madagascar [5, 6]. Today the most important producers of cloves are Indonesia (which is also, the main consumer), Tanzania (Zanzibar and Pemba islands) and Madagascar, which is the first world exporter with annual average exported quantities of 11000 tons for cloves and 1500 tons for essential oils [7].

Cloves can be used in cooking, either whole or in ground form. The spice is used throughout Europe and Asia and is smoked in cigarettes also known as "kreteks" in Indonesia. Cloves are also an important incense material in Chinese and Japanese cultures [8].

Clove essential oils are extensively used in the flavour and fragrance industry. On account of various biological activities, clove essential oils are extensively used in dental formulations, tooth paste, breath freshner, mouth washes, soaps, cosmetic items and insect repellent $[8,9]$. The oil possesses antiemetic, analgesic, antibacterial, antifungal and anticarcinogenic properties [10-15]. The chief constituent of clove essential oil is eugenol, which is used as a starting material for the production of vanillin [16].

The chemical composition on bud, leaf and stem oil of $S$. aromaticum has been recently studied by Razafimamonjison et al. (2013) [3]. They found that the major constituent in bud, leaf and stem oils was eugenol, with increasing percentages from bud $(72.08-82.36 \%)$ to leaf $(75.04-83.58 \%)$ and stem $(87.52-96.65 \%)$. In bud essential oils, eugenyl acetate is the second major component $(8.6-21.3 \%)$ while detected in considerably lower amount in leaf $(0-$ $1.45 \%)$ and stem $(0.07-2.53 \%)$. In leaf essential oils, the second main compounds were $\beta$-caryophyllene (11.65 $19.53 \%)$ and $\alpha$-humulene $(1.38-2.17 \%)$, less represented in bud essential oils $(2.76-8.64 \%$ and $0.34-1.04 \%$ respectively) and in stem essential oils (1.66 - 9.7\% and $0.22-1.31 \%$ respectively). 
However to the best of our knowledge there is no data available regarding the change in essential oil yield and composition of clove bud from Madagascar throughout its phenological stages. Hence, the present study describes the essential oil yield and composition of $S$. aromaticum buds in different phenological stages.

\section{Materials and methods}

\subsection{Plant material}

Cloves buds of $S$. aromaticum were collected at different phenological stages from three individual trees, named 1,2 and 3, grown in the region Atsinanana of Madagascar, fokontany Analamalotra (S $18^{\circ} 05^{\prime} / \mathrm{E} 049^{\circ} 21^{\prime}$ ). Harvesting time was stretched monthly in July 2012 (young bud) to February 2013 (full fruiting). Thus, 24 samples were used in this study. Full details of phenological stages, harvesting time and physical characteristics (length, dry weight and moisture content) of $S$. aromaticum buds are provided in Table 1.

Table 1: Phenological stages, harvesting time and physical characteristics of S. aromaticum buds collected at Analamalotra (Madagascar).

\begin{tabular}{|c|c|c|c|c|c|c|c|}
\hline $\begin{array}{l}\text { Stages } \\
\text { code }\end{array}$ & $\begin{array}{l}\text { Phenological } \\
\text { stages }\end{array}$ & Harvesting time & Bud Color & $\begin{array}{l}\text { Lenght } \\
\text { (mm/bud) }\end{array}$ & $\begin{array}{l}\text { Dry weight } \\
\text { (mg/bud) }\end{array}$ & $\begin{array}{l}\text { Moisture content } \\
(\%)\end{array}$ & Sample code \\
\hline $\mathrm{A}$ & Young bud & July 2012 & Green & $5.88 \pm 1.43 \mathrm{a}$ & $13.23 \pm 6.15 \mathrm{a}$ & $47.63 \pm 1.04 \mathrm{a}$ & $\mathrm{A} 1, \mathrm{~A} 2, \mathrm{~A} 3$ \\
\hline B & Budding 1 & August 2012 & Green & $6.18 \pm 1.47 \mathrm{a}$ & $13.68 \pm 7.01 \mathrm{a}$ & $48.23 \pm 2.56 \mathrm{a}$ & $\mathrm{B} 1, \mathrm{~B} 2, \mathrm{~B} 3$ \\
\hline $\mathrm{C}$ & Budding 2 & September 2012 & Green & $10.75 \pm 1.06 \mathrm{~b}$ & $41.97 \pm 9.66 b$ & $53.47 \pm 1.83 \mathrm{~b}$ & $\mathrm{C} 1, \mathrm{C} 2, \mathrm{C} 3$ \\
\hline $\mathrm{D}$ & Budding 3 & October 2012 & Pale yellow & $13.31 \pm 1.20 \mathrm{c}$ & $61.23 \pm 12.98 \mathrm{c}$ & $57.57 \pm 1.01 \mathrm{c}$ & D1, D2, D3 \\
\hline $\mathrm{E}$ & Full budding & November 2012 & Yellow to pink & $17.80 \pm 0.93 \mathrm{~d}$ & $83.81 \pm 8.49 \mathrm{c}$ & $70.64 \pm 0.83 \mathrm{~d}$ & $\mathrm{E} 1, \mathrm{E} 2, \mathrm{E} 3$ \\
\hline $\mathrm{F}$ & Flowering & December 2012 & Red & $21.45 \pm 0.91 \mathrm{e}$ & $334.55 \pm 20.90 \mathrm{~d}$ & $71.48 \pm 1.06 \mathrm{e}$ & $\mathrm{F} 1, \mathrm{~F} 2, \mathrm{~F} 3$ \\
\hline $\mathrm{G}$ & Initial fruiting & January 2013 & Red & $24.38 \pm 1.74 \mathrm{f}$ & $449.95 \pm 29.85 \mathrm{e}$ & $74.63 \pm 0.82 \mathrm{f}$ & $\mathrm{G} 1, \mathrm{G} 2, \mathrm{G} 3$ \\
\hline $\mathrm{H}$ & Full fruiting & February 2013 & Dark red & $25.93 \pm 2.49 \mathrm{~g}$ & $531.13 \pm 32.72 \mathrm{f}$ & $79.56 \pm 0.95 \mathrm{~g}$ & $\mathrm{H} 1, \mathrm{H} 2, \mathrm{H} 3$ \\
\hline
\end{tabular}

The cloves bud color was adopted as a visual ripening criterion. In fact, the clove buds turned from green (young bud) to pale yellow (budding stage 3) and yellow to pink towards the full budding stage, to dark red when completely ripe (Table 1). Moisture content was determined using the thermobalance type Sartorius MA 45 , at $130^{\circ} \mathrm{C}$ temperature and the rate of weight loss was $4 \mathrm{mg}$ per $24 \mathrm{sec}$.

\subsection{Essential oil extraction}

$100 \mathrm{~g}$ of fresh clove buds from each tree were subjected to hydrodistillation using a Clevenger apparatus over $4 \mathrm{~h}$ [17]. The oils obtained were separated from water by decantation, dried over anhydrous sodium sulphate $\left(\mathrm{Na}_{2} \mathrm{SO}_{4}\right)$ and yield percentage was calculated as volume of essential oil per $100 \mathrm{~g}$ of plant dry matter weight. The extracted oils were stored at $4{ }^{\circ} \mathrm{C}$ in the dark until analyses.

\subsection{Physicochemical characteristics}

The physicochemical characteristics were determined according to the Association Française de Normalisation (AFNOR): relative density (NF T 75-111/ISO 279:2000) and refractive index (NF T 75-112/ISO 280:2000) [18].

\subsection{Gas chromatography (GC-FID)}

Essential oils were analyzed by gas chromatography (GC) using Focus GC equipped with a flame ionization detector (FID) and capillary column (polyethylene glycol: $30 \mathrm{~m}$ x $0.25 \mathrm{~mm}$ i.d, $0.25 \mu \mathrm{m}$ film thickness). The flow of the carrier gas $\left(\mathrm{N}_{2}\right)$ was $1 \mathrm{ml} / \mathrm{min}$ and the split ratio 1:10 (1 $\mu 1$ 10:100 heptane solution). Temperature was programmed to increase from 60 to $180^{\circ} \mathrm{C}$ at the rate of $7^{\circ} \mathrm{C} / \mathrm{min}$. Injector and detector temperatures were respectively held at 230 and $250{ }^{\circ} \mathrm{C}$.

\subsection{Identification and quantification of components}

Component identification was carried out by comparing the retention indices (RI) relative (determined to the retention times of a series of n-alkanes) with those of the Adams data library [19]. Quantitative analysis of each oil component, expressed in relative percentage of area, was carried out by peak area normalization measurement.

\subsection{Statistical analysis}

The average \pm standard deviation of dry weight, length of clove buds and moisture content were calculated monthly from the values of "bulk" of 30 buds from three trees. The analysis of variance (ANOVA) using XLSTAT Version 2012 statistical software package was applied to compare the effects of different phenological stages on dry weight, length, moisture, density relative, refractive index and yield oil of cloves buds. If the null hypothesis of means equality was rejected with a probability threshold of $\mathrm{p} \leq 0.05$, the analysis was pursued using Fisher's test at a probability threshold of $\mathrm{p} \leq 0.05$. In tables and figures, values with different subscript were significantly different at $\mathrm{p} \leq 0.05$. The 
distribution of the 24 samples was analyzed by Principal Component Analysis (PCA) and by Agglomerative Hierarchical Clustering analysis (AHC) using the XLSTAT Version 2012 statistical software package. The data set was composed of the values taken by four variables identified by GC and the 24 clove bud oil samples. PCA and AHC were performed as they are among the best-known multivariate analysis methods for variable correlation determination [20, $21]$.

\section{Results and discussion}

\subsection{Physicochemical characteristics}

The oils obtained are slightly viscous with the clove characteristics of warm, pale yellow color, spicy odor and clove flavor, devoid of any harshness. Following phenological stages, the density relative and the refractive index measurements exhibited a gradual increase from 1.021 to 1.056 (Fig. 1) and from 1.5126 to 1.5423 (Fig. 2), respectively.

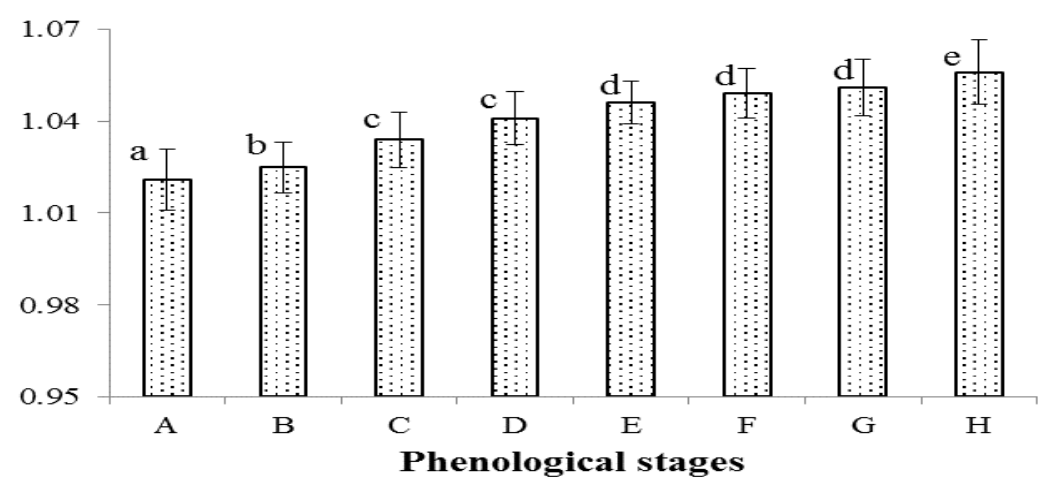

Fig.1: Density relative of the essential oil of $S$. aromaticum buds following the eight phenological stages. In each trait, mean with different subscript ( $\mathrm{a}$ - e) were significantly different at $\mathrm{p} \leq 0.05$ (Fisher's test). A, B, C, D, E, F, G, H represents young bud stage, budding stage 1 , budding stage 2 , budding stage 3 , full budding stage, flowering stage, initial fruiting stage, full fruiting stage respectively.

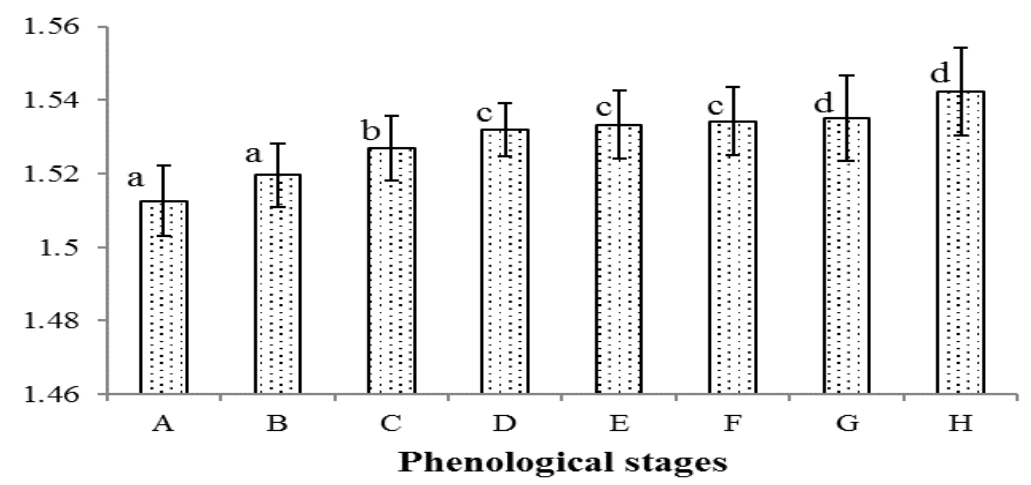

Fig.2: Refractive index of the essential oil of s. aromaticum buds following the eight phenological stages. In each trait, mean with different subscript (a - d) were significantly different at $\mathrm{p} \leq 0.05$ (fisher's test). A, B, C, D, E, F, G, H: Same as in Fig 1.

\subsection{Essential oil yield}

Following the eight phenological stages, essential oil yield of S. aromaticum buds varied from $2.52 \%$ to $17.94 \%$, reaching a maximum at the end of budding stage, after which it rapidly decreased (Fig. 3). According to the ANOVA analysis (Fisher test, using a significance level of $\mathrm{p} \leq 0.05$ ) the essential oil yield showed four phases. In the first phase, remarkable lower variation in oil content was observed from young bud stage (17.58\%) to full budding stage (17.94\%). During the second phase (flowering stage), the oil contents decreased rapidly to be $12.25 \%$. In the third phase (initial fruiting stage), the oil content decreased continuously and was detected at $9.46 \%$. The last phase (full fruiting stage) was characterized by lowest amount of essential oil yield about $2.52 \%$. Based on these results, we calculated that the maximum essential oil production occurred in the full budding stage (17.94\%), which has rarely been reported in other plants [22-24]. 


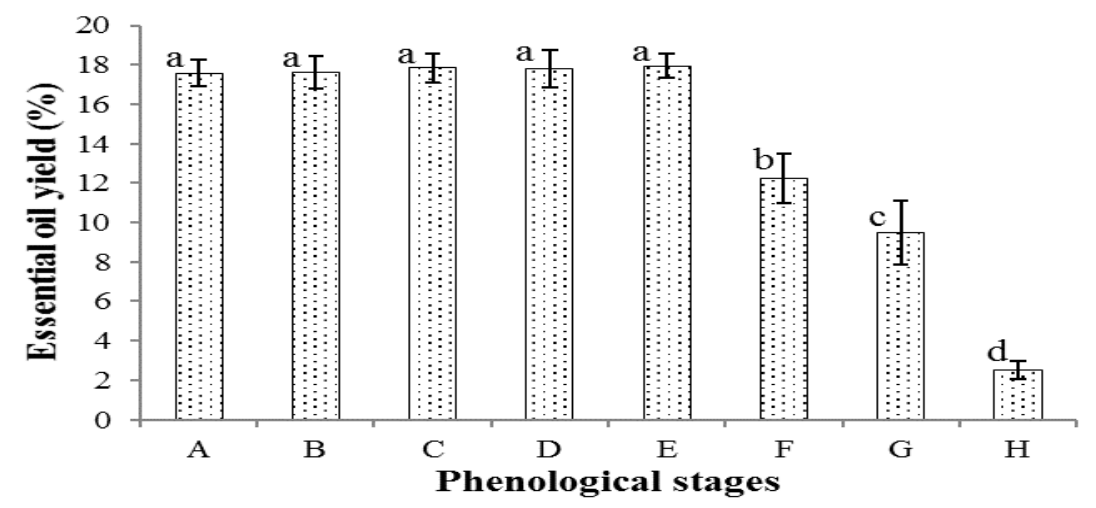

Fig.3: Evolution in essential oil yield (\%, V/W) S. aromaticum buds following the eight phenological stages. In each trait, mean with different subscript (a - d) were significantly different at $\mathrm{p} \leq 0.05$ (Fisher's test). A, B, C, D, E, F, G, H: Same as in Fig 1.

\subsection{Essential oil composition}

The 24 samples of $S$. aromaticum buds oil were analyzed by GC and four constituents, $\beta$ - caryophyllene, caryophyllene oxide, eugenol and eugenyl acetate, were identified and quantified, as shown in table 2. These four identified compounds constituted from $97.98 \%$ (young bud stage) to $99.54 \%$ (budding stage 2) of the total integrated GC peak area at the all phenological stages (Table 2). Eugenol and eugenyl acetate were the main compounds in all samples. Eugenol, was lower in the young bud stage (39.66\%) and increased in the subsequent phenological stages to reach maximum in the full fruiting stage $(94.89 \%)$. In contrast, eugenyl acetate was higher in the young bud stage $(56.07 \%)$, after which decreased to reach minimum in the full fruiting stage $(2.01 \%)$.

Table 2: Chemical composition (relative percentages, mean \pm SD) of essential oil from S. aromaticum bud following the eight phenological stages. A, B, C, D, E, F, G, H: Same as in Fig 1.

\begin{tabular}{|c|c|c|c|c|c|c|c|c|c|}
\hline \multirow[b]{2}{*}{ Compounds } & \multirow[b]{2}{*}{ RI } & \multicolumn{4}{|c|}{ Chemical pattern 1} & \multicolumn{4}{|c|}{ Chemical pattern 2} \\
\hline & & $\mathrm{A}$ & $\mathrm{B}$ & $\mathrm{C}$ & $\mathrm{D}$ & $E$ & $\mathrm{~F}$ & $\mathrm{G}$ & $\mathrm{H}$ \\
\hline$\beta$-caryophyllene & 1595 & $1.77 \pm 0.21$ & $2.01 \pm 0.43$ & $0.80 \pm 0.04$ & $2.27 \pm 0.75$ & $0.62 \pm 0.21$ & $0.37 \pm 0.06$ & $1.03 \pm 0.69$ & $1.99 \pm 0.87$ \\
\hline caryophyllene oxide & 1976 & $0.48 \pm 0.12$ & $0.74 \pm 0.63$ & $0.27 \pm 0.13$ & $0.25 \pm 0.15$ & $0.06 \pm 0.03$ & $0.27 \pm 0.09$ & $0.60 \pm 0.19$ & $1.01 \pm 0.61$ \\
\hline eugenol & 2151 & $39.66 \pm 3.45$ & $42.16 \pm 1.51$ & $49.97 \pm 0.90$ & $52.13 \pm 1.59$ & $87.78 \pm 0.77$ & $93.68 \pm 0.88$ & $94.48 \pm 0.77$ & $94.89 \pm 0.66$ \\
\hline eugenyl acetate & 2263 & $56.07 \pm 0.93$ & $54.44 \pm 1.06$ & $48.5 \pm 1.05$ & $44.00 \pm 1.53$ & $10.68 \pm 1.02$ & $4.22 \pm 0.90$ & $2.53 \pm 1.13$ & $2.01 \pm 0.54$ \\
\hline Total identified & & $97.98 \pm 2.02$ & $99.35 \pm 0.25$ & $99.54 \pm 0.38$ & $98.65 \pm 0.50$ & $99.13 \pm 0.16$ & $98.55 \pm 0.78$ & $98.63 \pm 1.22$ & $98.56 \pm 1.26$ \\
\hline
\end{tabular}

To highlight the effects of phenological stages on composition of S. aromaticum buds oil, PCA were carried out on 24 samples considering four variables (four components identified by GC). The results of the statistical analysis were as follows:

The first two principal components (Fig. 4) extracted by PCA explains $90.16 \%$ of the variability of which $58.96 \%$ was represented by $\mathrm{PC} 1$ and $31.20 \%$ by PC2. PC1 is principally structured by eugenol with a positive correlation (0.88) and one variable with negative correlation eugenyl acetate $(-0.80)$.

The PCA according to planes PC1 and PC2 made it possible to distribute the 24 samples analyzed into two Chemical Patterns (Table 2 and Fig. 5).

The first chemical pattern is constituted by all samples collected at young bud stage (A1 - A3), all samples gathered at the budding stage $1(\mathrm{~B} 1-\mathrm{B} 3)$, all samples harvested at the budding stage $2(\mathrm{C} 1-\mathrm{C} 3)$ and all samples collected at the budding stage 3 (D1 - D3). This first chemical pattern is characterized by lower content in eugenol (39.66-52.13\%) and higher percentage of eugenyl acetate $(56.07-44.00 \%)$.

The second chemical pattern is composed of 12 samples which are characterized by higher content of eugenol (87.78 $94.89 \%)$ and lower percentage of eugenyl acetate $(10.68-2.01 \%)$. This second chemical is constituted by all samples harvested at full budding stage (E1 - E3), all samples gathered at flowering stage (F1 - F2), all samples collected at initial fruiting stage $(\mathrm{G} 1-\mathrm{G} 2)$ and all samples harvested at full fruiting stage $(\mathrm{H} 1-\mathrm{H} 2)$. 


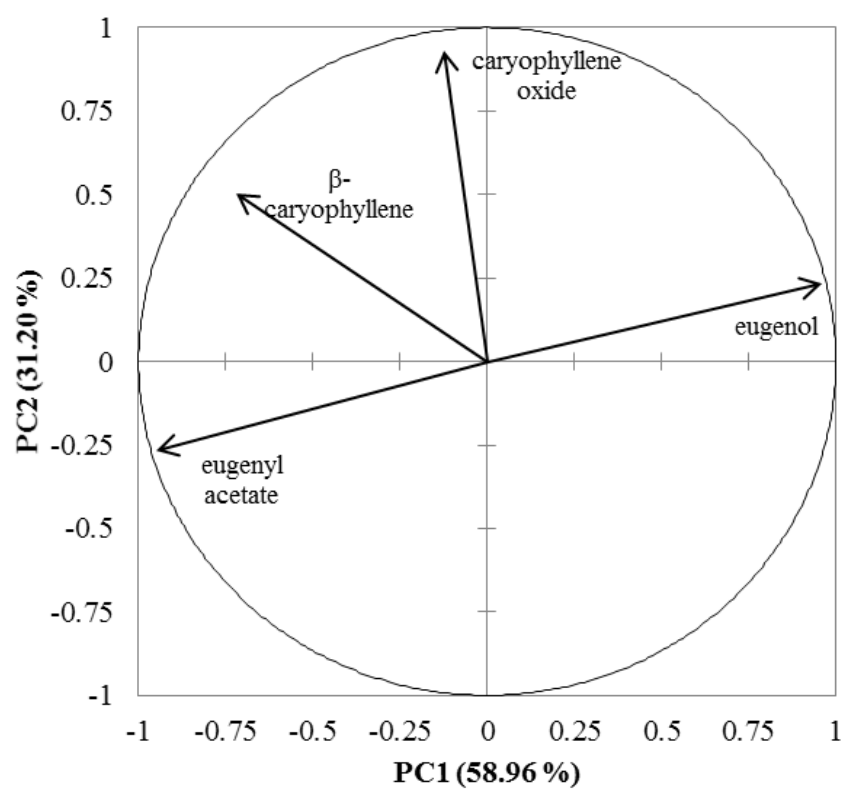

Fig.4: Circle of correlations of the four examined variables of S. aromaticum oil by the first two principal components (PC1/PC2).

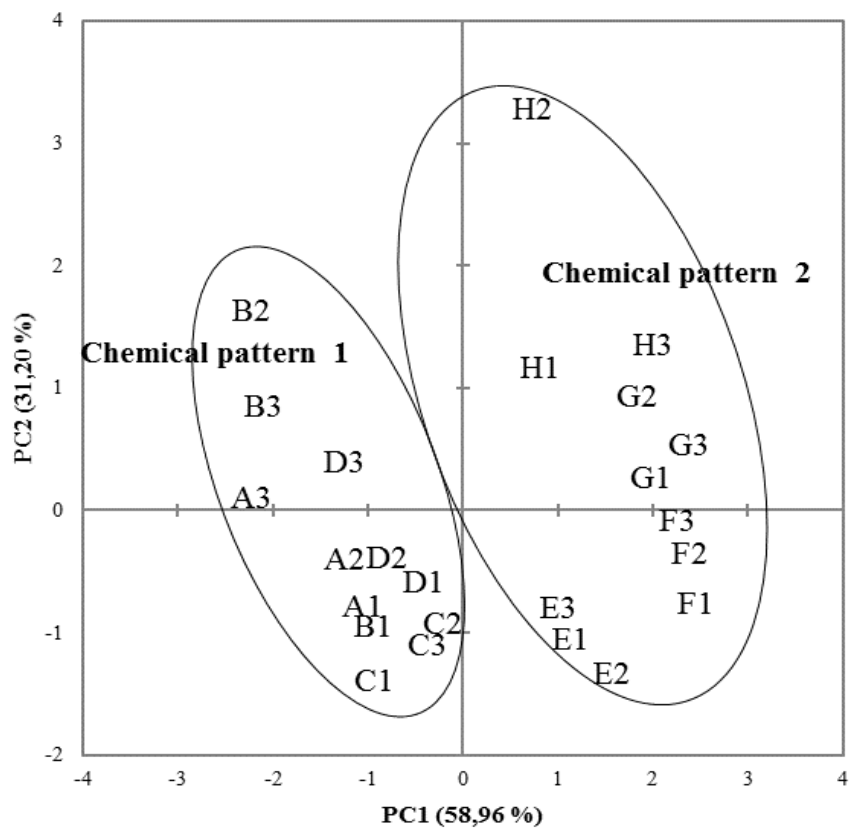

Fig.5: Graphical representation of the 24 samples of clove bud essential oil using pca according to PC1/PC2. A, B, C, D, E, F, G, H: Same as in Fig 1. 1,2 and 3 individual tree name.

An agglomerative hierarchical clustering analysis has been computed on the data. No assumption is made concerning the number of groups or the group structure. We used the single linkage criteria (smallest distance, i.e. nearest neighbour) applied to the matrix of euclidean distances (taking the four variables into consideration) between the 24 individual samples. The results of this single linkage clustering are graphically shown in the dendrogram on Fig. 6 . Two clusters, clearly apparent, confirm the distribution of the 24 samples into two chemicals patterns already shown by PCA (Table 2 and Fig. 5). The first cluster corresponds to the chemical pattern 1 and the second cluster corresponds to the chemical pattern 2 . 


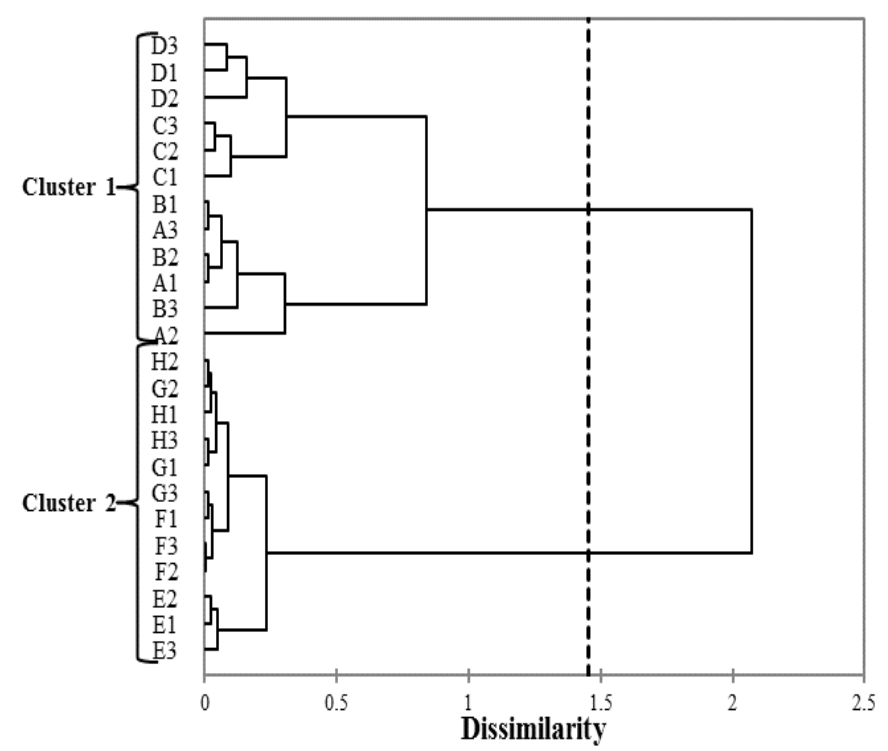

Fig.6: Single linkage dendrogram of the hierarchical clustering for euclidean distances between the 24 individual samples of cloves buds essential oil. A, B, C, D, E, F, G, H: same as in fig 1. 1, 2 and 3 individual tree name.

\section{Conclusion}

In this study, we investigated the yield and the chemical composition of the essential oil isolated from S. aromaticum buds from Madagascar during different phenological stages, which has not been reported in other research. The most significant differences between the eight phenological stages were the changes in essential oil content and in the percentages eugenol and eugenyl acetate. According to our results, the best time to harvest clove bud for their essential oil is in full budding stage to obtain the highest amount of yield and eugenol. This result confirms the knowledges of the farmers by collecting cloves at this stage of development.

\section{Acknowledgements}

Financial assistance was gratefully received from the French Ministry of Foreign Affairs (FSP PARRUR).

\section{References}

[1] A. Ledreux, "Le giroflier à Sainte Marie et à Madagascar", Extrait de l'Agronomie Coloniale, Bulletin mensuel de l'Institut Nationale d'Agronomie Coloniale, 175 - 176, (1932), $22 \mathrm{p}$.

[2] G. Vernin, E. Vernin, J. Metzger, L. Pujol, C. Parkanyi, "GC/MS analysis of clove essential oils. In Spices Herbs and Edible Fungi", Charalambous G (Ed.). Elsevier Science: Amsterdam, (1994), 483 - 500.

[3] G. Razafimamonjison, M. Jahiel, T. Duclos, et al., "Bud, leaf and stem essential oil composition of clove (Syzygium aromaticum L.) From Indonesia, Madagascar and Zanzibar." Natural Product Communications (sous presse), (2013).

[4] J. Maistres, "Plantes à épices. Paris: Maisonneuve et Larose - Séries: Techniques agricoles et productions tropicales", (1964), 32 p.

[5] J. Maistres, "Le giroflier de Madagascar et Zanzibar", Agronomie tropicale, 10, (1955), 415 - 448.

[6] P.J. Martin, "The Zanzibar clove industry", Economic Botany, 45, 4, (1991), 450-459.

[7] INSTAT, "(Institut National de la Statistique Malgache). URL: http://www.instat.mg/", (2012). [On line]. [14.11.2012].

[8] M.H. Alma, M. Ertas, S. Nitz, H. Kollmannsberger, "Chemical composition and content of essential oil from the bud of cultivated Turkish clove (Syzigium aromaticum L.)", BioRessources, 2, 2, (2007), 265 - 269.

[9] H.M. Kim, E.H. Lee, S.H. Hong, et al., "Effect of Syzygium aromaticum extract on immediate hypersensitivity in rats", Journal of Ethnopharmacology, 60, (1998), 125 - 131.

[10] F. Chami, N. Chami, S. Bennis, T. Bouchikhi, A. Remmal, "Oregano and clove essential oils induce surface alteration of Saccharomyces cerevisiae", Phytotherapy Research, 19, (2005), 405 - 408.

[11] M. Miyazawa, M. Hisama, "Suppression of chemical mutagen induced SOS response by alkylphenols from clove (Syzygium aromaticum) in Salmonella typhymurium." Journal of Agricultural and Food Chemistry, 49, (2001), 4019 - 4025.

[12] M. Ogata, M. Hoshi, S. Urano, T. Endo, "Antioxidant activity of eugenol and related monomeric and dimeric compounds", Chemical \& Pharmaceutical Bulletin, 48, (2000), 1467 - 1469.

[13] I.K. Park, S.C. Shin, "Fumigant activity of plant essential oils and components from garlic (Allium sativum) and clove bud (Eugenia caryophyllata) oils against the Japanese termite (Reticulitermes speratus)", Journal of Agricultural and Food Chemistry, 53, (2005), 4388 4392. 
[14] T. Tworkoski, "Herbicide effects of essential oils", Weed Science, 50, 4, (2002), 425 - 431.

[15] G.Q. Zheng, P.M. Kenney, L.K.T. Lam, "Sesquiterpenes from clove (Eugenia caryophyllata)", Journal of Natural Products, 55, (1992), 999 1003.

[16] A.K. Srivastava, S.K. Srivastava, K.V. Syamsundar, "Bud and leaf essential oil composition of Syzygium aromaticum from India and Madagascar", Flavour and Fragrance Journal, 20, (2005), 51 - 53.

[17] J.A. Pino, R. Marbot, J. Aguero, V. Fuentes, "Essential oil from buds and leaves of clove (Syzigium aromaticum L. Merr. et Perry) Grown in Cuba", Journal of Essential Oil Research, 13, (2001), 278 - 279.

[18] AFNOR, "Recueil de normes: Les huiles essentielles. Tome 2. Monographies relatives aux huiles essentielles ", AFNOR, Paris, (2000), 661 663.

[19] R.P. Adams, "Identification of essential oils components by Gas Chromatography / Quadrupole Mass Spectrometry, 4th Ed., Allured Publishing Corporation, Carol Stream", (2007), 1 - 804.

[20] H.S. Andrianoelisoa, C. Menut, P. Collas de Chatelperron, et al. "Intraspecific chemical variability and highlighting of chemotypes of leaf essential oils from Ravensara aromatica Sonnerat, a tree endemic to Madagascar", Flavour and Fragrance Journal, 21, (2006), 833-838.

[21] M. Rakotobe, C. Menut, H.S. Andrianoelisoa, et al., "The bark essential oil composition and chemotaxonomical apparaisal of Cedrelopsis grevei $\mathrm{H}$. Baillon from Madagascar", Natural Product Communications, 3, (2008), 1 - 6.

[22] S.N. Ebrahimi, J. Hadian, M.H. Mirjalili, A. Sonboli, M. Yousefzadi, "Essential oil composition and antibacterial activity of Thymus caramanicus at different phenological stages", Food Chemistry, 110, (2008), 927 - 931.

[23] E. Németh, E. Héthelyi, J. Bernath, "Comparison studies on Tanacetum vulgare L. chemotypes", Journal of Herbs, Spices \& Medicinal Plants, 2, 2, (1994), $85-92$

[24] S. Ramezani, F. Rasouli, B. Solaimani, "Changes in Essential Oil Content of coriander (Coriandrum sativum L.) Aerial parts during four phenological stages in Iran", Journal of Essential Oil Bearing Plants, 12, 6, (2009), 683 - 689. 